\title{
Historical areas of misiones as heritages: critical reflections for a communal archaeology proposal
}

Keywords: heritages of humanity, iguazú falls, argentina, cultural organization, archeology

\section{Introduction}

The Province of Misiones, located in the northeastern part of Argentina, is an area that represents diverse and socially known attractions or elements. Among them are the sites or areas denominated "Heritage of Humanity", seal given by UNESCO (the United Nations Educational, Scientific and Cultural Organization), come across. These heritages are: the Iguazù falls; a natural area formed by multiples cascades, situated in the humid subtropical rainforest and which has an important flora and fauna diversity. Beside this, the Guaranì Jesuit missions, ancient colonial sites or actual "ruins", where the urban settlements of the Jesuit missions (also called reductions) used to work. Although in the triple frontier region formed by the territories of Argentina, Paraguay and Brazil, thirty Jesuit reductions are identified, in the UNESCO list, particularly in the Argentinean territory are only the ancient reductions of Santa Ana, Nuestra Señora de Loreto, Santa María la Mayor and San Ignacio Miní. Nevertheless, it is evident that the last one is the most touristic and resourceful place, even exceeding its loading capacity, it leaves the other reductions less visited and with little activities going on. From this perspective and taking into account the historical legacy that the GuaraníJesuit missions represent, we expect to discuss and reflect about the relationship between archeological heritages, local communities and their connection as regard patrimonial assets. Since the case of a study based on a historical town called Concepción de la Sierra, where the ancient reduction of Nuestra Señora de Ibitiracua was located, it can be analysed how the local communities appropriate sites and material goods from the past, in order to built "archeological heritages that are altered and modified over the course of time", avoiding elitist categories of international organisms. Arguing from the case of the study already mentioned and considering the multiples historical

\author{
Volume 3 Issue I - 2018
}

\author{
Amanda Eva Ocampo \\ Universidad Nacional de Misiones, Argentina
}

Correspondence: Amanda Eva Ocampo, Universidad Nacional de Misiones, Argentina, Tel 5438I62487I0,

Email amiocampo25@gmail.com

Received: February 01, 2018 | Published: February 16, 2018

towns of Misiones, it is essential to mention that the archeological materiality present on the everyday nature of communities expresses a historical continuity between the indigenous people from the past and the ones at the present. From the archeological sites, spatial reuse and its current historical heritage, the town of Concepcion de la Sierra develops a challenge to the way of creating traditional archeology, as the different temporalities that constitute the present of a town can no longer be left out of the study (Figure 1).

Finally, we look forward to discussing which the role of archeology as a disciplinary practice is and which elements should be considered when working and acting on projects that have a regional context where the overwhelming, strong and profitable tourism plays an influential role. We present as alternative work proposals, the realization of permanent cultural workshops in multiple spaces of the town and, in this way, we invite all the community to create an integrating space of debate in terms of future works from projects of investigation in connection with people's desires that arrive to the workshops and the perception of their own heritages.
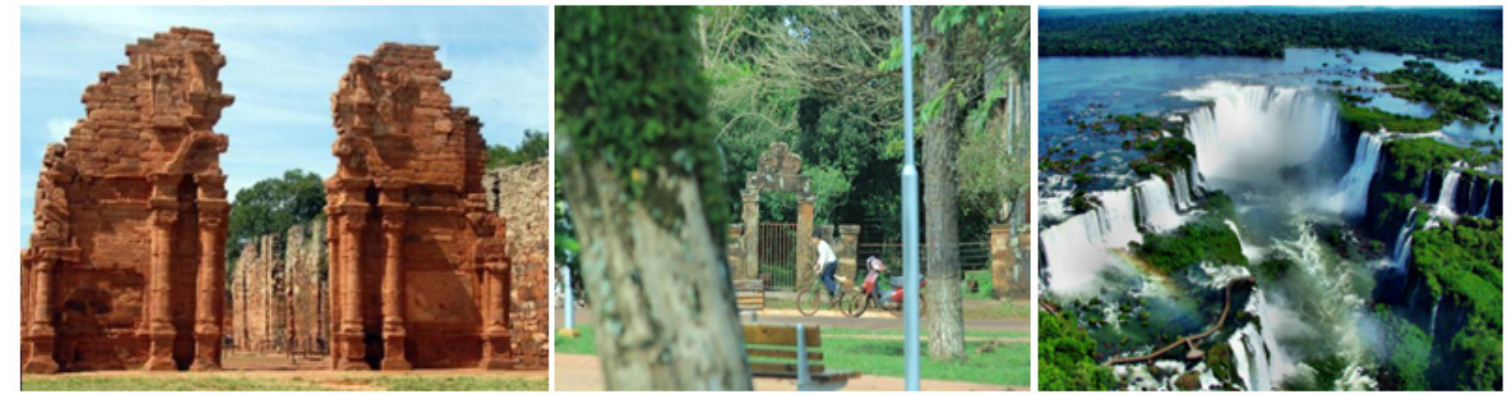

Figure I (Images from left to right) Reduction of San Ignacio Miní, general view of the historical center of Concepcion de la Sierra and the lguazú falls.

Archeological heritage of concepcion de la sierra

Although this work is not focused on the historical local background, in general terms, we can determine that the historical centre of Concepcion de la Sierra was a Guaraní Jesuit reduction founded in 1619 by the Saint Father Roque Gonzalez de Santa Cruz.
This educational place had been part of the natural and colonial surrounding that existed in the territory on that time. Even though it is not exactly as it was in its time of rebirth and fulfillment, a connection between the past and the present can be observed by means of materiality. Beginning with spare parts and different Saints' statues as a starting premise and as an identifying aspect in the case of the study of Concepcion de la Sierra, we discover several reused places. 
The town is part of an ancient settlement which shows an urban layout of Jesuit reduction that is similar to the others from Misiones but that, nevertheless, still has some differences. However, it is under the actual urban layout and it is not out of the everyday nature of the town, since it is not presented as a tourist attraction as other places of the province. In fact, it is a great part of the inhabitants' lives.

The current dynamism of the archeological area does not offers passive scenes but historical territories typical of the everyday life in the town. Taking as references to Curtoni and Parades, "There is a landscape that was taken as an ethnographic, historical and archeological evidence which allows us to perceive and observe the footprint of events and the results of the group and individual activities of the local community as well as the type of relation that this town has with the territory" From this general overview, it is that we observe the dynamism of the spatial reuse in an ancient Guarani Jesuit reduction, formed by numerous materials and by archeological contexts which are being studied at the present day. It is also essential to determine, in an integral way, appropriate heritage policies between the project of investigation and the local actors.

\section{A past of or for the humanity?}

As we mentioned before and taking a case of study as an example, we would like to describe critically the province of Misiones and its relation to the serious heritage policy aimed at tourism exclusively. For this, we leave out projects related to social and scientific investigations including heritage awareness measures. Firstly, Misiones is wellknown by its "heritages of humanity" such as the Iguazú falls and the Guaraní- Jesuit missions; particularly the ruins of San Ignacio Miní These places attract tourism from all over the world, making the State rise financial resources exclusively from them. In this way, they create evident differences on the urban level and in the infrastructure in comparison with the other townships. Based on the regional context, we ask ourselves: Does the past belong to the humanity as a whole? Although the answer is worldwide known and important organisms, like UNESCO, have set suitable arguments about this matter, it is still necessary to know if we know which the people's position is or at least at which extent the past has influenced the communities in which we are working on.

In the case of the " heritages of humanity", the organization which has made the difference is the international organism called UNESCO (the United Nations Educational, Scientific and Cultural Organization), which has as main principle "to create the conditions for dialogue among civilizations, cultures and peoples, based upon respect for commonly shared values" (www.unesco.org ). In addition, among its multiples and broad aims, they boast of creating intercultural dialogue through education, the sciences, culture, communication and information. Unfortunately, it had been impossible to reach to an agreement between local authorities and the people of the community where the heritage is taken from. Since there are not any experiences related to reality, there is a risk categorizing historical areas with universal values that do not apply to our situation; it is a triple frontier region with patrimonial dynamism in a constant process of transformation. Such dynamism makes some heritages, as is the case of the historical centre of Concepción de la Sierra, to limit the way of thinking and defining them as an isolated concern which is homogenous and external to individuals and society in general.

In support of the cultural outcry, the remaining historical and archeological materials are conceived mainly as resources for touristic exploitation. However, local communities have limited participation in terms of the management of those resources and its correlation to touristic and cultural proposals or activities. In addition, in the case of Misiones and its Guaraní-Jesuit legacy, there are places that are visited by a great number of tourists and which have not been studied from an archeological point of view and have not been protected with suitable plans for their conservation. Thus, considering the current situation of the archeological and historical heritage of Concepcion de la Sierra and how certain guidelines of international organisms have no relation to local heritage experiences, we aim to link the archeological materiality to the awareness of an appropriate heritage policy for the management not only of attractive touristic circuits, but also to a social value, which contribute to improve inhabitants' living standard in connection with a legacy inclusion.

\section{Defending proposals and local alternatives}

Considering mainly the provincial heritages and historical villages as old reductions we propose the following points to define what the heritage is or at least, how we address the subject in the projects of investigation we had integrated. The legacy implies social expressions in which certain processes proper of different societies and periods, related to material impacts, are legitimized as something worthy of being studied, conserved and valued, that is to say that they are socially appreciated. The last point is, perhaps, the most complex one at the time of facing it from the archeological point of view as there is lack of knowledge/awareness in the inhabitants and local authorities. Even though these material manifestations were carried out in the past, they became determined as patrimonial goods based on the value given in cultural contexts. As a result they are currently reused and handled as well. In this way, an appropriate usage must include an integral management system which considers all the dimensions. The last point is perhaps the most complex one at the time of facing it from the archeological point of view as there is lack of knowledge in the inhabitants and local authorities.

From the analysis of the Guaraní Jesuit missions and their material manifestations as distinctive features of the colonial period, we try to "add a symbolic meaning to the cultural heritage". At the same time, it makes the region being an historical and remembered event. Besides, it is crucial to mention that there is a conditioning social-cultural context because of the fact that there is no cultural heritage without a sense of belonging; and, in order to have a recognized by individual's heritage, they should take it as their own. This sense of belonging idea, particularly in Concepción de la Sierra, does not allow us to put aside the legacy. In order to integrate the community in the projects of archeological research, we have carried out, as a first stage, some cultural workshops. The first experience, called "Conociendo las Historias de mi Región", was done in 1014 at "La casa de la Cultura" in Concepción de la Sierra.

Starting from different activities and the developing of specific topics such as archeology, history and cultural heritage, we set out a collective construction of consciousness about what the cultural heritage of Concepcion de la Sierra means as well as which are the numerous stories that must be told. This is the main goal of this stage, which consists on the contribution, by means of the narration of various/diverse experiences, to the memory of the place and its assessment and conservation. Summing up, the workshop had positive results because of, for example, the creation of a document which was presented in "La casa de la cultura" and in the local authority office, 
where the assistants proposed us different activities of patrimonial settlement. To mention some of them:

a. To get the reconditioning of the Ex Cabildo, this allows access to those people who want to visit it.

b. To take contact with the director of the Udeondo Museum ( Lujan town, Buenos Aires Province) in order to achieve the reconstruction of sculptures that belong to this town and that are conserved within that cultural centre (San José, Santa Verónica and Santa Bárbara)

c. To foster, before the Honorable Concejo Deliberante, the promulgation of an ordinance which proclaims the historical center as a matter of cultural interest.

Consequently, to achieve the observation of the historical materials which are sometimes used for housing and to declare them a subject-to-control interest? So in this way, establishing the necessity of having a compulsory permission with those materials is eventually used. After this first experience, the next research group's goal is to accommplish the second stage of the cultural workshop called "El Patrimonio jesuítico-guaraní de nuestra región. Hacia una propuesta de turismo comunitario en Concepción de la Sierra", to be achieved at the end of 2016 .

\section{Discussion}

\section{The challenges of the communal archeology}

In view of the activities and experiences carried out by the investigation department based on the study of the Guaraní-Jesuit settlements from Misiones, we adopted recent perspectives that has been implemented in the archeological field and which, also, make communities to establish dialogue. This premise involves starting to think about the outlining of the strategies in a communal archeology in which professionals must be awarded of new proposal and ideas from the local villages. On the account of this, the antecedent of the undertaken project of extension became a really important tool. In our case, all of them are related to patrimonial activation concerns. The challenge is to include Archeology when planning research tasks considering the relation among heritages, history and community. It means that we study not only the educational past situation but also the connection with the present.

As a result, we establish dialogues between local knowledge that includes everyday life experiences and the archeological places we want to study and conserve. In this way, we will make a specific approach to the cultural dynamism that considers a multifocal perspective. The historical legacy of the towns of Misiones requires hard teamwork; and its main challenge is to determine alternatives avoiding imposed neutral studies or approaches with a lack of communal presence. From the local point of view, it is essential to describe Archeology as a science that studies human societies. Yet, it does not have the recognition that other regions, like the northwestern part of Argentina do. It is necessary to establish a relation between the research project and the cultural tourism. So people from Misiones would feel part of the numerous social processes that had been carried out in the regions and also it would make them notice "the ones which are not from here". For future work, it will be vital to determine a method to create communal archeology and generate an active role among patrimonial policies by means of local factors and by avoiding international and inert categories that do not have to be with the historical territory of Misiones.

Summing up, this work was addressed with the idea of reflecting the main points that can be established from an Archeological point of view. It was crucial to establish the existing relation in the communities that are present in the heritage and the archeological areas we had studied. Also, it was a starting point that helped us to go out from the exclusively technical and scientific studies that the academy demands. In view of local people and researchers, it is set out the searching of a non-elite practice in relation to research and management of the archeological and historical legacy. Based on the research made in Concepcion de la Sierra, we suggest that the archeological areas keep changing over the time. This is a clear evidence of being of the social projects and trajectories which create identities. We do not have uninhabited deserts but a society that promote the place.

The work also adopted an attitude that questions the patrimonial policies of UNESCO. This is accompanied with a demanding tourism lacking of information. Therefore, we discuss about the protection of the archeological heritage, particularly the Guaraní-Jesuit missions. On the other hand, we focused on activities that allow us to establish a communal archeology. It aimed to the heritage activation of local agents from the promotion of active areas between them and the researchers. Following Jofre, we consider that each inhabitant of Misiones contributes to a collective construction of knowledge, on the local memorial spaces. Finally, in this work we tried to contribute and support the idea of changing the vision of the archeological heritages in relation to past events without considering the present time, the silent testimony of a lost world. It is crucial to assume which are the responsibilities we have as students of the ancient town's history with a concrete commitment to the current towns.

\section{Acknowledgements}

None.

\section{Conflict of interest}

Author declares that there is no conflict of interest. 